\title{
A comparison of auditory evoked potentials in two species of sparrow
}

\author{
ROBERT J. DOOLING and MARGARET H. SEARCY \\ Rockefeller University, Millbrook, New York 12545
}

\begin{abstract}
Auditory evoked potentials were recorded from the surface of the brain in young swamp and song sparrows. Responses to pure tones indicate that both species have similar auditory sensitivity during the sensitive period for song learning. Responses to the song syllables extracted from the normal adult song of both species show evidence of hemispheric differences for swamp sparrows listening to conspecific syllables but not to song sparrow syllables. Song sparrows showed no evidence of selective responsiveness to conspecific syllable type.
\end{abstract}

The swamp sparrow (Melospiza melodia) and the song sparrow (Melospiza georgiana) are two closely related species for which the phenomenon of selective vocal learning has been demonstrated. When reared in the laboratory under controlled conditions and tutored with the vocalizations of both species during the sensitive period for song learning, both species tend to learn only conspecific song while finding the song of the other species unacceptable for imitation (Marler \& Peters, 1977, 1981). An understanding of the mechanisms underlying selective vocal learning is important because it bears on the general problem of species recognition and because there are thought to be some parallels between the development of normal vocal behavior in song birds and the acquisition of speech in humans (Marler, 1970).

Several recent studies of vocal learning and song recognition in swamp and song sparrows have sought to determine the acoustic parameters involved. Playback studies in the field indicate that syllable morphology influences the discrimination of conspecific song from song-sparrow song in adult swamp sparrows, but temporal pattern does not. On the other hand, species song recognition is influenced by both syllable morphology and temporal pattern in adult song sparrows (Peters, Searcy, \& Marler, 1980). A recent examination of the cardiac orienting response in the young of both species indicates that swamp sparrows can discriminate their own species song from that of the song sparrow upon first hearing these songs (Dooling \& Searcy, 1980). These results suggest a perceptual component of selective vocal learning which may be innate.

The present study examines auditory evoked potentials recorded from young swamp and song spar-

We thank Joseph Hutt for programming assistance and Esther Arruza for manuscript preparation. This research was supported by Grant PHS MH31165 from NIMH to the first author. R. J. Dooling is now at the Department of Psychology, University of Maryland, College Park, Maryland 20742. rows during the sensitive period for song learning to gain further understanding of the process of selective vocal learning. We sought to determine (1) the absolute sensitivity of both species during the sensitive period for song learning, (2) the effect of repetition rate of a tonal stimulus on the evoked potential across species and across hemispheres, and (3) the effect of selected portions of natural vocalizations of both species on the evoked potential across species and across hemispheres.

\section{METHOD}

\section{Subjects}

Five swamp sparrows and five song sparrows were taken from the nest when only a few days old and raised by hand in the laboratory. During this hand-rearing period, all 10 sparrows were acoustically isolated from the adult vocalizations of either species except for the test stimuli. At the time of testing, the subjects ranged in age from 40 to 73 days.

\section{Recording Methods}

The active electrodes for recording auditory evoked potentials were modified amphenol connector pins insulated except at the tip with baked epoxylite. When they were between 3 and 7 weeks of age, the birds were anesthetized with $.08 \mathrm{cc}$ of chloropent and mounted in a stereotaxic holder. The skin over the skull was retracted, the bone dried, and small burr holes drilled over the left and right hemispheres $2.0 \mathrm{~mm}$ from the midline at the bregma. The electrode tip was lowered onto the surface of the dura and cemented in place with dental acrylic. A stainless steel screw placed on the midline a few millimeters behind the bill served the dual function of indifferent electrode and mounting point for a head holder. This recording configuration was selected on the basis of pilot experiments on both species, previous evoked potential studies in other birds (Dooling \& Walsh, 1976), and the known anatomy of the ascending auditory pathway in birds (Karten, $1967,1968)$. The birds were allowed a minimum of several days to recover from the effects of anesthesia and surgery before testing.

Testing was conducted with the birds awake but restrained in a custom-built holding device that left the head and body stationary and the ears unobstructed. All testing was conducted in an IAC sound chamber. Stimuli were delivered through a TDH-49 earphone mounted $10 \mathrm{~cm}$ directly in front of the bird's head. EEG potentials were conveyed via shielded cables to a Grass Model 7D polygraph with a 7P5A wide-band preamplifier. The band pass 
of these amplifiers was set from 1 to $500 \mathrm{~Hz}$. The outputs of the Grass amplifiers were distributed to the analogue inputs of an AR11 module of a PDP-11/10 computer.

\section{Testing Procedure}

For the assessment of absolute sensitivity, evoked potential waveforms consisting of 128 points were collected simultaneously from each hemisphere at the rate of $1,000 \mathrm{~Hz}$. Averaged evoked potentials were collected to pure tones from 500 to $8,000 \mathrm{~Hz}$ over about a $40-\mathrm{dB}$ range of intensities at each frequency. The actual intensities used were slightly different for each frequency but within the range of 20 to $60 \mathrm{~dB}$ SPL. Tone duration was kept constant at $20 \mathrm{msec}$ with $5-\mathrm{msec}$ rise/fall times. Stimuli were presented at the rate of 1 tone burst $/ 320 \mathrm{msec}$.

For a given frequency, evoked potentials to different intensities were obtained with an automated descending/ascending procedure. At each intensity, evoked potential waveforms from both hemispheres were the sum of evoked potentials to 256 tone bursts presented in eight blocks of 32 each. Starting at the highest intensity, evoked potentials to 32 stimulus presentations were summed and stored in memory. Intensity was then decreased a predetermined amount, and evoked potentials to another 32 stimulus presentations were summed and stored in a separate location in memory. This procedure continued in an alternating descending-thenascending fashion until evoked potentials to a total of 256 stimulus presentations were obtained at each intensity. The frequency of the tone burst was then set to a new test frequency, and the procedure was repeated. The order of frequencies tested was randomized, and a different random order was used for each bird.

The effect of repetition rate on the size of the evoked potential was also determined for both hemispheres of both species. A $2-\mathrm{kHz}$ tone burst was presented at an intensity of $60 \mathrm{~dB}$ SPL. Averaged evoked potentials were simultaneously recorded from both hemispheres to 256 tone-burst presentations at each of four interstimulus intervals of $80,160,320$, and $640 \mathrm{msec}$. As before, the order of tests was randomized and a different random order was used for each bird. To eliminate the possibility that slight differences in amplifier circuits or cable leads might contribute to any hemispheric differences found in this phase of the experiment, the EEG leads were switched at the animal and the entire experiment was repeated. Averaged waveforms from the first test and the second test were then added together, resulting in an $\mathrm{n}$ of 512 for each hemisphere and interstimulus interval.

In the final phase of this experiment, evoked potentials were collected to segments of natural vocalizations of each species. Four swamp sparrow syllables and four song sparrow syllables were computer-extracted from normal song (Zoloth, Dooling, Miller, \& Peters, 1980), recorded on audiotape, equated for a peak sound pressure level of $60 \mathrm{~dB}$ SPL, and presented at the rate of 1 syllable $/ 300 \mathrm{msec}$. As described above, averaged evoked potentials represented the sum of 256 presentations of a syllable. After evoked potentials were obtained to all eight syllables, EEG leads were again switched at the animal and the procedure was repeated. Thus, the averaged evoked potentials used for further analysis were the sum of the first and second runs. Each waveform represented a total of 512 stimulus presentations for each syllable and each hemisphere.

The nomenclature system previously used in describing and analyzing parakeet evoked potentials was also used in this study (Dooling \& Walsh, 1976). Approximate latencies to the major peaks $b, c$, and $d$ were determined from evoked potentials pooled across subjects for a given stimulus. A latency range for each stimulus was arbitrarily selected for each peak at $\pm 5 \mathrm{msec}$ for the first positive peak " $b, " \pm 15 \mathrm{msec}$ for the first negative peak " $c$," and $\pm 20 \mathrm{msec}$ for the second positive peak "d." Peaks were automatically calculated for individual waveforms according to these latency criteria. Amplitude measures a to b, b to $c$, and $c$ to $d$ as well as the associated latencies to peaks b, c, and d were selected for further analyses.

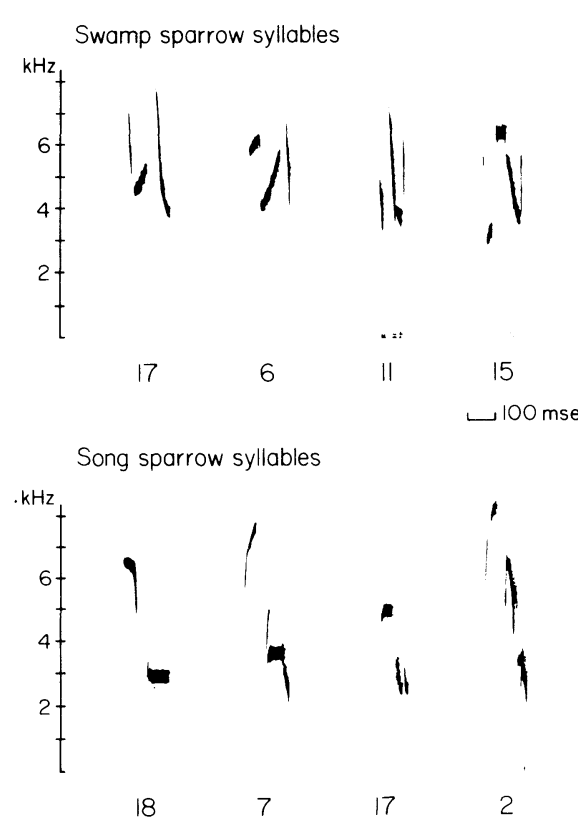

Figure 1. Spectrograms are shown for four swamp sparrow syllables (top) and four song sparrow syllables (bottom). The horizontal time marker represents 100 msec. Each syllable is also identified by a number.

\section{RESULTS}

Both swamp and song sparrows gave similar evoked potentials to the $20-\mathrm{msec}$ tone bursts described by a positive peak at about $19 \mathrm{msec}$, a negative peak at about $60 \mathrm{msec}$, and a second positive peak at about $100 \mathrm{msec}$ following stimulus onset. There were no systematic differences between hemispheres in these evoked potentials for either swamp or song sparrows. The waveforms were therefore pooled across hemispheres for the determination of absolute auditory sensitivity. Threshold was determined in two ways. Since the range of intensities chosen included belowthreshold intensities, a visual detection level could be estimated at each frequency. In addition, a regression line fit to above-threshold amplitude measures provides a treshold measure based on the $\mathrm{X}$ intercept or SPL corresponding to a $0-\mathrm{V}$ response amplitude (Dooling \& Walsh, 1976). The largest peak-to-peak difference, b-c, was used in both cases. Thresholds determined from the regression line method were generally 5-10 dB below the visual detection level. Auditory sensitivity was taken as the average of the results of these two methods of threshold estimation for both species. These results are shown in Figure 2. Both species show greatest sensitivity at $1 \mathrm{kHz}$ with thresholds elevated below and above this frequency. The dotted lines are pilot data obtained from two adult swamp and song sparrows using recording procedures similar to those employed in this study (Dooling, Note 1). We conclude that the thresholds 


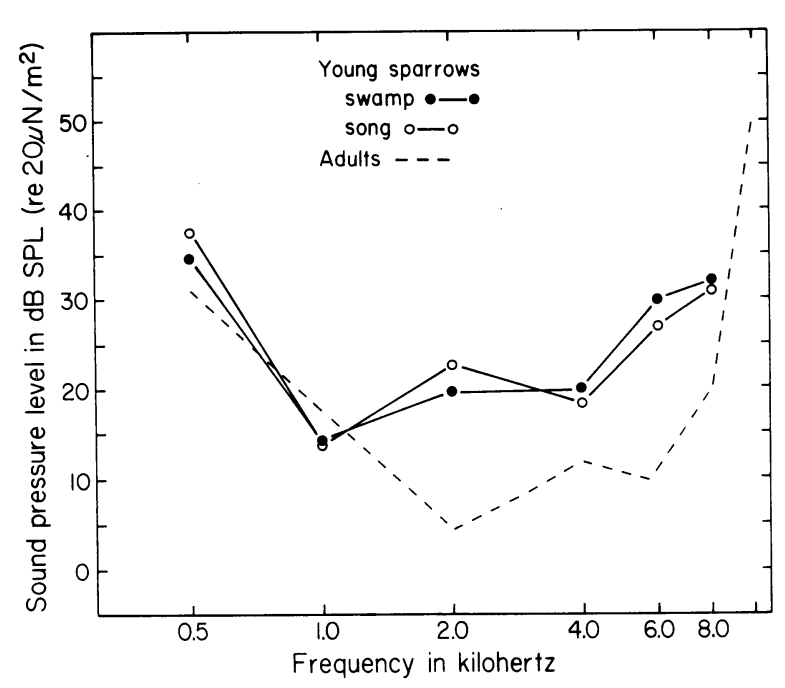

Figure 2. Evoked potential audibility curves are shown for young swamp and song sparrows (solid lines). For comparison, a composite audibility function based on data from two adult swamp sparrows and two adult song sparrows collected under similar recording conditions is also shown.

for young swamp and young song sparrows are quite similar during the period of several weeks following hatching.

The effect of interstimulus interval on the amplitude of the auditory evoked potential was also very similar for both species. A two-way analysis of variance (ANOVA) with repeated measures on factors A and $B$ was used to test for differences between hemispheres for each of the three amplitude and latency measures. There were no differences between hemispheres for either species on any of these six measures (Table 1). The largest peak-to-peak amplitude measure, b-c, was averaged across hemispheres, and the mean amplitude is shown for both swamp and song sparrows in Figure 3.

In a linear-log plot, a straight line adequately describes the data for both species. A similar relation has been found for other vertebrates, including man (Butler, 1973; Nelson \& Lassman, 1968). Differences in the temporal organization of adult song of these two species might suggest that the interstimulus interval would provide a cue for selective vocal learning during the sensitive period for song learning. We conclude, on the basis of the relation between evoked potential amplitude and repetition rate, that both species are sensitive, to a similar degree, to changes in interstimulus interval over the range of 80 to $640 \mathrm{msec}$.

Auditory evoked potentials resulting from the presentation of swamp and song sparrow syllables were generally more complex than those in response to pure tones. Still, there was little difficulty in locating the points of maximum excursion of the evoked potential waveform and labeling them in the conventional manner as peaks b, $c$, and d. Examples of evoked potential waveforms obtained from both hemispheres of both a swamp and a song sparrow are shown in Figure 4. The stimulus is the same (SWP No. 17) in all four cases, and an oscillogram of the stimulus is shown in approximate temporal relation to the evoked potential waveforms. Note the similarity in the shape of the evoked potential both across species and across hemispheres within an individual. This consistency facilitated the selection of the latency ranges of peaks b, c, and d from the pooled waveforms. An example of pooled waveforms from the left and right hemispheres of swamp sparrows to syllable swamp 17 is shown in Figure 5. The peaks b, c, and d are labeled appropriately.

A single-classification, two-level, nested ANOVA (Sokal \& Rohlf, 1969) was used to test for differences in evoked potential amplitude and latency measures between swamp sparrow vocalizations and song sparrow vocalizations. Each hemisphere of each species was tested separately. There was a tendency in both species for evoked potentials to be larger to song sparrow syllables than to swamp sparrow syllables. However, none of these differences on any of the amplitude measures reached statistical significance. There were also no significant differences for either species in the latencies to peaks b, c, and d.

Tests for hemispheric differences in the evoked potential to extracted natural syllables were performed in two ways. First, differences between the left and right hemispheres were tested directly, using a twoway ANOVA with repeated measures on factors A (hemispheres) and B (vocalizations) (Meyers, 1972).

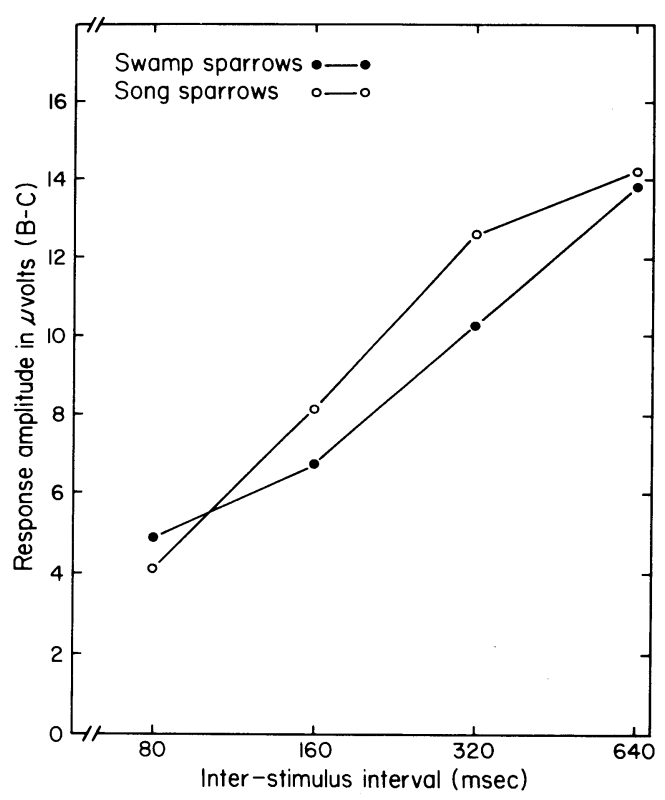

Figure 3. Evoked potential rate functions are shown for both species of sparrow. Evoked potential amplitude increases with increases in interstimulus interval. 


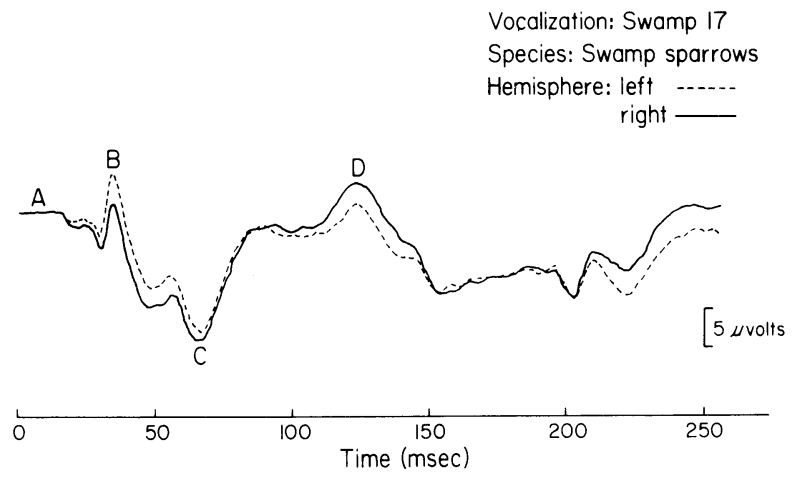

Figure 4. Grand mean evoked potentials from all five swamp sparrows are shown from the left (dashed line) and right (solid line) hemispheres. Vertical marker represents $5 \mu \mathrm{V}$. Evoked potential peaks used in subsequent analyses are identified by letters of the alphabet.
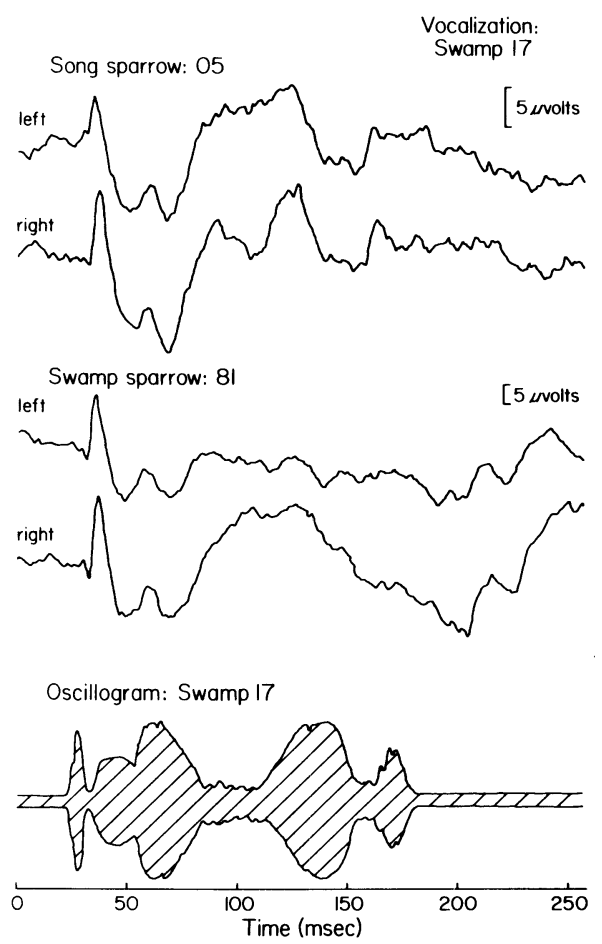

Figure 5. Evoked potentials from each hemisphere of two individuals are shown. The top pair of waveforms are from a song sparrow, and the lower pair of waveforms are from a swamp sparrow. An oscillogram of the syllable (swamp No. 17) is shown for comparison.
Evoked potentials from the previous experiment, using a $2-\mathrm{kHz}$ tone at various repetition rates, served as a reference condition against which to assess any differences. All significant $\mathrm{F}$ scores are given in $\mathrm{Ta}$ ble 1. The important findings are the following. There were no significant hemispheric differences on any amplitude or latency measure for either species when the stimulus was a $2-\mathrm{kHz}$ pure tone. There were, however, significant hemispheric differences on some measures when the stimuli were natural syllables. Specifically, swamp sparrows had a significantly larger left-hemisphere response to both swamp and song sparrow syllables on the $a-b$ amplitude measure. Song sparrows showed a significantly larger left-hemisphere response to both swamp and song sparrow syllables on the b-c amplitude measure. On amplitude measure c-d, swamp sparrows showed a significantly larger right hemispheric response to conspecific syllables alone and not to song sparrow syllables. Both species showed significant hemispheric differences in the latencies to peak $b$ when presented with song sparrow syllables but not with swamp sparrow syllables. This effect was also different for the two species in that swamp sparrows showed a shorter latency in the left hemisphere than in the right hemisphere, while song sparrows showed exactly the reverse. No other amplitude or latency measures showed significant hemispheric effects.

Both the amplitude and latency results can also be described in terms of a laterality index, $L /(L+R)$, with the advantage that a hemispheric difference can be represented by a single number that expresses the difference as a percent of the total possible difference (Matsumiya, Tagliasco, Lombrosco, \& Goodglass, 1972). Such a laterality index was computed for each amplitude and latency measure for each species, and a single-classification, two-level, nested ANOVA (Sokal \& Rohlf, 1969) was used to test for differences in the laterality index obtained with swamp sparrow syllables as compared with song sparrow syllables. Of the three amplitude and latency measures available for each species, the only significant difference occurred for swamp sparrows on the c-d amplitude measure. Swamp sparrows showed a significantly smaller laterality index $(R>L)$ in response to conspecific syllables than in response to song sparrow syllables $[F(1,6)=11.34, p<.025]$. In

Table 1

F Scores for Hemispheric Differences

\begin{tabular}{|c|c|c|c|c|c|c|c|c|c|c|c|c|}
\hline & \multicolumn{6}{|c|}{ Swamp Sparrows } & \multicolumn{6}{|c|}{ Song Sparrows } \\
\hline & \multicolumn{3}{|c|}{ Amplitude } & \multicolumn{3}{|c|}{ Latency } & \multicolumn{3}{|c|}{ Amplitude } & \multicolumn{3}{|c|}{ Latency } \\
\hline & $\mathrm{A}-\mathrm{B}$ & $\mathrm{B}-\mathrm{C}$ & C-D & B & $\mathrm{C}$ & $\mathrm{D}$ & A-B & $\mathrm{B}-\mathrm{C}$ & C-D & B & $\mathrm{C}$ & $\mathrm{D}$ \\
\hline Swamp Vocalizations & $7.69 \dagger$ & n.s. & $6.19^{*}$ & n.s. & n.s. & n.s. & n.s. & $13.27 \dagger$ & n.s. & n.s. & n.s. & n.s. \\
\hline Song Vocalizations & $5.98 *$ & n.s. & n.s. & $4.97 *$ & n.s. & n.s. & n.s. & $5.10^{*}$ & n.s. & $4.56^{*}$ & n.s. & n.s. \\
\hline 2-kHz Tone & n.s. & n.s. & n.s. & n.s. & n.s. & n.s. & n.s. & n.s. & n.s. & n.s. & n.s. & n.s. \\
\hline
\end{tabular}

Note $-d f=1,28 . \quad{ }^{*} F=4.20(p<.05) . \quad \dagger F=7.64(p<.01)$. 


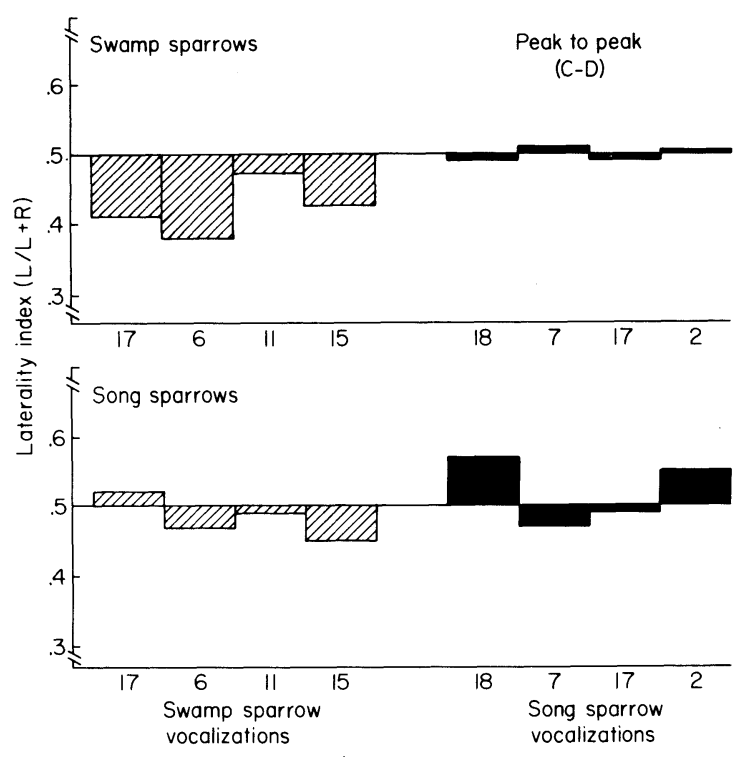

Figure 6. Based on peak-to-peak amplitude measures c-d, the average laterality indices for the set of natural stimuli are shown for both species of sparrow. Swamp sparrows show a significantly larger right hemispheric response to conspecific syllables (hatched bars) than to song sparrow syllables (solid bars). Song sparrows show no significant hemispheric response across the two sets of stimuli.

comparison, the laterality indices for swamp sparrows listening to song sparrow syllables show no hemispheric differences, as was the case for the $2.0-\mathrm{kHz}$ pure tone (laterality index $=.49$ ). Song sparrows showed no significant differences in the laterality indices across vocalizations or for the $2.0-\mathrm{kHz}$ pure tone (laterality index $=.48$ ). These results are shown in Figure 6. An identical result is obtained if the comparison is based on a baseline-to-positive peak $d$ amplitude measure.

At the conclusion of these experiments, all but one of the birds could be sexed by laparotomy. One of the swamp sparrows was a male, and two of the song sparrows were males. There were no significant differences between the evoked potentials of males and females in any of these experiments.

\section{DISCUSSION}

Previous research on the differences in song learning between these two species of sparrow indicate that swamp sparrows are highly selective in what syllables they choose for imitation (Marler \& Peters, 1977) and that some degree of this selectivity is innate (Dooling \& Searcy, 1980; Marler \& Peters, 1981). The present results are relevant to the possible mechanisms involved in these species differences in several ways.

First, the auditory evoked brain potential demonstrates that young swamp and song sparrows have identical auditory sensitivity during the sensitive period for song learning. Thresholds from young birds approach the levels of sensitivity for adult birds at low frequencies but show poorer sensitivity at middle and high frequencies than is typical of song birds (Dooling, 1980). Furthermore, evoked potential rate functions were nearly identical across species and across hemispheres. Thus, at the level of the evoked potential, there is no evidence for species differences in temporal processing, which may help explain the gross differences in the temporal organization of the adult songs of these two species (Marler \& Peters, 1977). This is perhaps not too surprising in view of more recent song learning data which indicate that temporal patterning is not a salient cue for young swamp sparrows and is only weakly effective in guiding the vocal learning process in song sparrows (Marler \& Peters, 1981).

Evoked potentials to the natural syllables of both species were generally more complex, with evidence for hemispheric differences. Both species showed larger evoked potentials to song sparrow syllables than to swamp sparrow syllables. This tendency is best explained by two facts. The evoked potential audiograms of both species showed maximum sensitivity to frequencies around $1.0 \mathrm{kHz}$, and a comparison of the average power spectra of the four swamp and song sparrow syllables showed slight spectral differences between these two sets of sounds. The song sparrow syllables used in these experiments have more energy in the region of maximum auditory sensitivity of both species than do the swamp sparrow syllables. There is no evidence in the comparison across vocalizations for either species of the operation of a process that could account for selective vocal learning.

Evoked potentials were collected from both hemispheres for all stimuli in order to test for the presence of hemispheric asymmetries, especially in the processing of species-specific sounds. The question of whether there are hemispheric asymmetries in the data is important. There is a considerable body of evidence suggesting possible parallels between language learning in humans and vocal learning in young song birds (Marler, 1970), including left-hemisphere dominance for vocal control (Nottebohm, 1980). Furthermore, there is evidence in humans of hemispheric asymmetry in the later positive components of evoked potential related to the perception of words and speech sounds (see, e.g., Cohn, 1971; Matsumiya et al., 1972; Morrell \& Salamy, 1971), although these asymmetries have also proven to be small and difficult to demonstrate (Galambos, Benson, Smith, Schulman-Galambos, \& Osier, 1975; Friedman, Simson, Ritter, \& Rapin, 1975).

The conditions in the present study were chosen to minimize stimulus and recording artifacts that might contribute to significant hemispheric effects. At the same time, conditions were chosen to maximize the probability of demonstrating hemispheric asymmetries. These conditions included using natural 
stimuli, recording from an awake animal preparation, and examining more than one aspect of the evoked potential waveform. Multiple comparisons using different components of the evoked potential were applied in identical fashion for both sets of natural stimuli and the neutral control stimulus in order to provide a proper comparison.

For both species, there were significant hemispheric effects that occurred when natural stimuli were presented and not when the control sound was presented. These differences, however, are difficult to interpret. On one component, swamp sparrows gave a larger left-hemisphere response to both swamp and song sparrow syllables, but, on another component, they gave a larger right(smaller left)-hemisphere response to only conspecific syllables. It is impossible to tell how these two effects may be related. Song sparrows showed a larger right-hemisphere response to both species' syllables on one component of the evoked potential waveform, but, unlike the swamp sparrows, showed no significant hemispheric effect on any component to conspecific syllables alone. The latency differences, while barely significant, are less than $1 \mathrm{msec}$ and are thus further confounded by the digitizing rate of 1 point $/ \mathrm{msec}$.

From the point of view of a species-specific perceptual process and as a possible parallel with the human case, the mose interesting finding is the significant difference in the later positive component of the evoked potential across vocalization class which occurs for swamp sparrows. The effect is one of a larger right-hemisphere response than left-hemisphere response, which occurs only to conspecific syllables for the swamp sparrow. This effect is in the direction opposite to that expected if swamp sparrows, like canaries, prove to show a left-hemisphere dominance for vocal control (Nottebohm, 1980). Similar experiments on a large number of adult birds will be required to resolve this issue. It may be, for instance, that the left hemisphere lags behind the right hemisphere in the development of responsiveness to conspecific vocalizations, but in adulthood shows a larger response.

The fact that only swamp sparrows showed any evidence of a species-specific response is important. The comparative data to date on vocal learning in these two species clearly show the swamp sparrow to be more selective initially than the song sparrow. This selectivity operates at the level of the syllable (Marler \& Peters, 1977) and can also be demonstrated in the cardiac orienting response of young swamp sparrows (Dooling \& Searcy, 1980). To the extent that hemispheric differences in the processing of vocal stimuli may be related to this early perceptual selectivity, the present results offer further support for the notion of differences in the process of vocal learning between these two species at the level of the perception of individual syllables.

\section{REFERENCE NOTE}

1. Dooling, R. J. Unpublished study, 1979.

\section{REFERENCES}

Butler, R. A. The cumulative effects of different stimulus repetition rates on the auditory evoked response in man. Electroencephalography and Clinical Neurophysiology, 1973, 35, 337-345.

CoHN, R. Differential cerebral processing of noise and verbal stimuli. Science, 1972, 172, 599-601.

Dooling, R. J. Behavior and psychophysics of hearing in birds. In A. N. Popper \& R. R. Fay (Eds.), Comparative studies of hearing in vertebrates. New York: Springer-Verlag, 1980.

Dooling, R., \& SeArcy, M. Early perceptual selectivity in the swamp sparrow. Developmental Psychobiology, 1980, 13, 499-506.

Dooling, R. J., \& Walsh, J. K. Auditory evoked response correlates of hearing in the parakeet (Melopsittacus undulatus). Physiological Psychology, 1976, 4, 224-232.

Friedman, D., Simson, R., RitTer, W., \& Rapin, I. Cortical evoked potentials elicited by real speech words and human sounds. Electroencephalography and Clinical Neurophysiology, 1975, 38, 13-19.

Galambos, R., Benson, P., Smith, T. S., Schulman-Galambos, C., \& Olsier, H. On hemispheric differences in evoked potentials to speech stimuli. Electroencephalography and Clinical Neurophysiology, 1975, 39, 379-383.

KARTEN, H. The organization of the ascending auditory pathway in the pigeon (Columba livia). I. Diencephalic projections of the inferior colliculus (nucleus mesencephalic lateralis pars dorsalis). Brain Research, 1967, 6, 409-427.

Karten, H. The ascending auditory pathway in the pigeon (Columba livia). II. Telencephalic projections of the nuclei ovoidalis thalami. Brain Research, 1968, 11, 134-153.

MARLER, P. Bird song and speech development: Could there be parallels? American Scientist, 1970, 58, 669-673.

Marle R, P., \& PEters, S. S. Selective vocal learning in a sparrow. Science, 1977, 198, 519-521.

Marler, P., \& Peters, S. S. Bird song and speech: Evidence for special processing. In P. Eimas \& J. Miller (Eds.), Perspectives on the study of speech. Hillsdale, N.J: Erlbaum, 1981.

Matsumiya, Y., TAgliasco, V., Lombrosco, C. T., \& Goodglass, H. Auditory evoked response meaningfulness of stimuli and interhemispheric asymmetry. Science, 1972, 175, 790-792.

Meyers, J. L. Fundamentals of experimental design (2nd ed.). Boston: Allyn \& Bacon, 1972.

Morrell, L., \& Salamy, J. Hemispheric asymmetry of electrocortical responses to speech stimuli. Science, 1971, 174, 164-166.

Nelson, D. A., \& Lassman, F. M. Effects of intersignal interval on the human auditory evoked response. Journal of the Acoustical Society of America, 1968, 44, 1529-1532.

Nоттевонм, F. Brain pathways for vocal learning in birds: A review of the first 10 years. In J. M. S. Sprague \& A. N. E. Epstein (Eds.), Progress in psychobiology and physiological psychology. New York: Academic Press, 1980.

Peters, S. S., Searcy, W. A., \& Marler, P. Species song discrimination in choice experiments with territorial male swamp and song sparrows. Animal Behaviour, 1980, 28, 393-404.

Sokal, R. R., \& Rohlf, F. S. Biometry. San Francisco: Freeman, 1969.

Zoloth, S., Dooling, R. J., Miller, R., \& Peters, S. A minicomputer system for the synthesis of animal vocalizations. Zeitschrift für Tierpsychologie, 1980, 54, 151-162.

(Manuscript received December 1980; revision accepted for publication August 4, 1981.) 